\begin{tabular}{|c|l|}
\hline Title & Comparison of warfarin sensitivity between rat and bird species \\
\hline Author(s) & Watanabe, Kensuke P.; Saengtienchai, A ksorn; Tanaka, Kazuy uki D.; Ikenaka, Y oshinori; Ishizuka, Mayumi \\
\hline Citation & $\begin{array}{l}\text { Comparative Biochemistry and Physiology Part C : Toxicology \& Pharmacology, 152(1), 114.119 } \\
\text { https://doi.org/10.1016/.cbpc.2010.03.006 }\end{array}$ \\
\hline Issue Date & 2010-06 \\
\hline Doc URL & http://hdl.handle.net/2115/43139 \\
\hline Type & article(author version) \\
\hline File Information & CBPC152-1_114_119.pdf \\
\hline
\end{tabular}

Instructions for use 


\section{Comparison of warfarin sensitivity between rat and bird species}

Kensuke P. Watanabe, Aksorn Saengtienchai, Kazuyuki D. Tanaka, Yoshinori Ikenaka, Mayumi Ishizuka

Laboratory of Toxicology, Department of Environmental Veterinary Sciences, Graduate School of Veterinary Medicine, Hokkaido University, N18 W9, Kita-ku Sapporo, 060-0818, Japan.

Corresponding author:

Mayumi Ishizuka

Laboratory of Toxicology, Department of Environmental Veterinary Sciences, Graduate School of Veterinary Medicine, Hokkaido University, N18 W9, Kita-ku Sapporo, 060-0818, Japan.

E-mail: ishizum@vetmed.hokudai.ac.jp

Telephone number: 011-706-5102

Fax number: 011-706-5105 


\begin{abstract}
Scattering coumarin-derivative rodenticides in broad areas have caused primary- and secondary-poisoning incidents in non-target wild birds. In this study, we compared factors determining warfarin sensitivity between bird species and rats based on vitamin K 2,3-epoxide reductase (VKOR) kinetics, VKOR inhibition by warfarin and warfarin metabolism assays. In VKOR characterization, chickens and ostriches showed significantly lower enzymatic efficiencies than rats (one-sixth and one-third, respectively), suggesting bird species depend more on a non-VKOR vitamin $\mathrm{K}$ source. On the other hand, the inhibition constants $\left(K_{i}\right)$ of VKOR for warfarin were significantly different between chickens and ostriches $(11.3 \pm 2.5 \mu \mathrm{M}$ and $0.64 \pm 0.39 \mu \mathrm{M}$, respectively). Interestingly, the ostrich $K_{i}$ was similar to the values for rats $(0.28 \pm 0.09 \mu \mathrm{M})$. The $K_{i}$ results reveal a surprising possibility that VKOR in some bird species are easily inhibited by warfarin. Warfarin metabolism assays also showed a large inter-species difference in bird species. Chickens and ostriches showed higher metabolic activity than that of rats, while mallards and owls showed only a slight ability to metabolize warfarin. In this study, we clarified the wide inter-species difference that exists among birds in xenobiotic metabolism and sensitivity to a rodenticide.
\end{abstract}

\title{
Keywords
}

Avian; Cytochrome P450 (CYP); Inhibitor constant $\left(K_{i}\right)$; Raptor; Vitamin K epoxide reductase (VKOR); Vitamin K; Warfarin 


\section{Introduction}

Coumarin derivative anticoagulants such as warfarin are commonly used for rodent control worldwide. The pharmacological target of these rodenticides is vitamin $\mathrm{K}$ 2,3-epoxide reductase (VKOR), which catalyzes the reduction of vitamin K 2,3-epoxide (VKO) and vitamin $\mathrm{K}$ (Figure 1). Because reduced vitamin $\mathrm{K}$ is required for the post-translational formation of $\gamma$-carboxyglutamyl residues from Glu residues in clotting factors II, VII, IX, and X (Suttie and Nelsestuen , 1980), the inhibition of VKOR by coumarin derivatives causes lethal hemorrhages in rodents (Thijssen et al., 2004; Cain et al., 1998). Meanwhile, coumarin derivative anticoagulants are metabolized by cytochrome P450 (CYP), which consists of a large number of isoforms. In rats, several forms of CYP are known to metabolize warfarin. Warfarin hydroxylation is mainly catalyzed by CYP2C, CYP2B, CYP1A, and CYP3A subfamilies in rats. The five hydroxides are identified as 4'-, 6-, 7-, 8- or 10-OH warfarin (Guengerich et al., 1982), and these primary metabolites are made more water-soluble by phase II enzymes (Jansing et al., 1992), and are excreted in urine.

At present, a coumarin derivative anticoagulant has been one of the most successful rodenticides for pest control. However, repeated use of this rodenticide has caused resistance in wild rodents. Resistance to warfarin in wild rodents was first observed in Scotland in 1958 (Boyle, 1960). Since then, resistance mechanisms have been intensely studied in rats, and recent research has shown that warfarin resistance can be explained by VKOR mutation and/or elevated warfarin metabolic activity (Lasseur et al., 2005; Ishizuka et al., 2007). These reports suggested the VKOR inhibition rate by warfarin and the metabolic activity of warfarin were important parameters leading to the development of sensitivity against warfarin.

To control the population of resistant rodents, a new generation of anticoagulants has 
been developed (Petterino and Paolo, 2001; Gebauer, 2007). These second-generation warfarins are called "superwarfarins," and include brodifacoum, bromadiolone, and difethialone. The target molecule of a superwarfarin and the mode of action is the same as those of the first-generation drugs, but superwarfarins have a generally prolonged half-life in the body (Vandenbroucke et al., 2008). After the increase of second-generation anticoagulant production in the marketplace, primary- and secondary-poisoning incidents from these anticoagulants in birds have drastically increased (Albert et al., 2009; Walker et al., 2008; Johnston et al., 2005; Eason et al., 2002; Dowding et al., 1999; Empson and Miskelly, 1999; Howald et al., 1999; Stone et al., 1999), even though one advantage of warfarin as a rodenticide was its relatively safety for non-target animals. Primary poisoning occurs by the consumption of anticoagulant-containing baits and secondary poisoning occurs by the consumption of rodents that were killed with rodenticides. In poisoning incidents, raptors such as owls or falcons are frequently reported to be affected, and it is assumed that they died from eating poisoned rodents.

In some species of birds, the $\mathrm{LD}_{50}$ of anticoagulants has been reported (Petterino and Paolo, 2001; Erickson and Urban, 2004). Strangely, it was shown that birds, e.g., chickens (Gallus gallus), ring-necked pheasants (Phasianus colshicus) and northern bobwhites (Colinus virginianus), are relatively or drastically resistant to anticoagulants not only compared with rats but also to other mammalian species (Table 1), although incidents involving non-target animals have mostly been reported in bird species.

One possibility, which indicates a disagreement between the reported data of high values of $\mathrm{LD}_{50}$ in laboratory birds and the frequency of non-target poisoning in wild birds, is large inter-species differences in the sensitivity of birds to rodenticides, e.g., differences in the VKOR inhibition rate or direct CYP metabolic pathway. However, those data are limited to a few species of birds, and the sensitivity to rodenticides by determining the VKOR 
characterization or warfarin clearance ability has not been systematically studied in birds.

In this paper, we elucidate the VKOR differences and warfarin metabolic activity in birds compared with laboratory rats, which are known to be sensitive to a coumarin derivative anticoagulant. The aim of this study was to clarify the inter-species differences in sensitivity against warfarin, one of the most commonly used rodenticides in the world. 


\section{Materials and Methods}

\subsection{Animals}

Four- to 5-week-old male chickens (Gallus gallus) were used in this study. They were housed in a 12 h light-and-dark cycle. They were sacrificed with $\mathrm{CO}_{2}$, and livers were immediately removed. Fresh livers of male ostriches (Struthio camelus) were donated by Hokkaido Ostrich Farm Kuroda (Hokkaido, Japan). The ostriches were 2-6 years old. The samples of male mallards (Anas platyrhynchos, 9 weeks old) were a kind gift from Hokuseien Farm (Horonobe, Japan). We also collected two liver samples from male snowy owls (Bubo scandiacus) from the Maruyama Zoo (Sapporo, Japan). One of them was 3 years old and died from aspiration pneumonia. The other snowy owl was 12 years old, and was assumed to have died from lung aspergillosis. Furthermore, one male great horned owl (Bubo virginianus) liver sample was also kindly gifted. This individual was 2 years old and the cause of death was unknown, but infectious disease and liver dysfunction were ruled out. In addition, as control animals, we used male Wistar rats (10 weeks old) to compare with birds. All rats were housed one per cage, under standard laboratory conditions (12 h light: $12 \mathrm{~h}$ dark) with food and water available ad libitum.

Treatments of all animals were performed according to the policies of the Institutional Animal Care and Use Committee of Hokkaido University (No. 15099 and No. 08-0331).

\subsection{Chemicals}

HEPES was purchased from Dojindo Laboratories (Kumamoto, Japan). Copper sulfate $\left(\mathrm{CuSO}_{4} 5 \mathrm{H}_{2} \mathrm{O}\right)$, vitamin $\mathrm{E}$ and vitamin $\mathrm{K}_{1}$ were from Kanto Chemicals (Tokyo, Japan). Bovine serum albumin (BSA), diethyl ether and racemic warfarin were from Sigma Aldrich Inc. (St. 
Louis, MO, United States). Warfarin-sodium, dithiothreitol (DTT), dichloromethane, ethanol, methanol, $\mathrm{H}_{2} \mathrm{O}_{2}, \mathrm{~K}_{2} \mathrm{HPO}_{4}, \mathrm{KH}_{2} \mathrm{PO}_{4}, \mathrm{MgCl}_{2}, \mathrm{Na}_{2} \mathrm{CO}_{3}, \mathrm{NaCl}, \mathrm{NaOH}$, perchloric acid, phenol reagent (Folin-Ciocalteu reagent) were purchased from Wako Pure Chemical Industries (Osaka, Japan). Glucose 6-phosphate (G6P), glucose 6-phosphate dehydrogenase (G6PDH) and $\beta$-NADPH were from Oriental Yeast Co. Ltd. (Tokyo, Japan). Warfarin metabolites (4'-, 6-, 7-, 8-, and 10-hydroxywarfarin) were obtained from Ultrafine Chemicals (Manchester, UK).

\subsection{Preparation of liver microsomes}

Livers were taken from animals, and liver microsomes were prepared according to the method of Omura and Sato (1964). The livers were homogenized with three times their volume of potassium phosphate buffer (KPB, 0.1 M, pH7.4). The homogenates were centrifuged at $9,000 \mathrm{~g}$ at $4^{\circ} \mathrm{C}$ for $20 \mathrm{~min}$. The supernatant was decanted to an ultracentrifugation tube and centrifuged at $105,000 \mathrm{~g}$ at $4^{\circ} \mathrm{C}$ for $60 \mathrm{~min}$. The pellet was homogenized in KPB in ice and then centrifuged again at $105,000 \mathrm{~g}$ at $4^{\circ} \mathrm{C}$ for $60 \mathrm{~min}$ for washing. The resultant microsomal pellets were homogenized in KPB again. The suspensions were transferred to $1.5 \mathrm{ml}$ tubes and stored at $-80^{\circ} \mathrm{C}$ until use. The protein concentration of microsomes was measured by the method of Lowry et al. (1951), and the P450 content was estimated following the method of Omura and Sato (1964).

\subsection{Kinetics studies on vitamin K epoxide reductase activities}

Vitamin $K_{1}$ epoxide was prepared according to the method of Tishler et al. (1940) and the concentration of vitamin $\mathrm{K}_{1}$ epoxide was determined spectrophotometrically using a molar absorption coefficient of 30,800 $\mathrm{M}^{-1} \mathrm{~cm}^{-1}$ at $266 \mathrm{~nm}$ (Wallin and Martin, 1987). The vitamin $\mathrm{K}_{1}$ 
epoxide was kept at $4^{\circ} \mathrm{C}$ and was shielded from light until use.

VKOR activity was assayed by a modified method of Lasseur et al. (2005) using microsomes. Microsomes were diluted in DDW and HEPES buffer (pH 7.4, $0.1 \mathrm{M}$, final concentration) to a final concentration of $1.0 \mathrm{mg} / \mathrm{ml}$ protein. The reaction mixture (total volume was $500 \mu \mathrm{l}$ ) contained 12.5, 25, 50, 100, 200, 300 and $400 \mu \mathrm{M}$ of vitamin $\mathrm{K}_{1}$ epoxide. Samples were pre-incubated for $5 \mathrm{~min}$, and the reaction was started by the addition of $2 \mathrm{mM}$ DTT solution in 0.1 M HEPES buffer. In the enzymatic reaction, we set the temperature as the physiological condition for each bird species. The temperature of pre-incubation and reaction was $37^{\circ} \mathrm{C}$ for rats, $38^{\circ} \mathrm{C}$ for ostriches and $42^{\circ} \mathrm{C}$ for chickens (Richards, 1971 ; Schmidt-Nielsen et al. 1969). The incubation time was $5 \mathrm{~min}$, and the reaction was stopped by the addition of 1 $\mathrm{ml}$ of iced dichloromethane containing vitamin $\mathrm{E}$ as an internal standard. To wash the solution, $0.5 \mathrm{ml}$ of $2 \% \mathrm{NaCl}$ solution was added and then $3.7 \mathrm{ml}$ dichloromethane, which contained vitamin $\mathrm{E}$ as an internal standard, was added to the extract. After centrifugation $(1,000 \mathrm{~g}, 10$ $\min$ ), the aqueous layer was removed by an aspirator. Then, $3 \mathrm{ml}$ of the dichloromethane layer was taken and evaporated by a centrifugal evaporator. The dry residue was immediately dissolved in $110 \mu \mathrm{l}$ of methanol containing 4\% DDW. Vitamin $\mathrm{K}_{1}$ and vitamin E were measured by high pressure liquid chromatography (HPLC) and quantified at $270 \mathrm{~nm}$ (Pump: PU-980 (JASCO), Detector: SPD-6AV (SHIMADZU)). Separation was archieved on a TSKgel-120T, $250 \times 4.6 \mathrm{~mm}, 5 \mu \mathrm{m}$ analytical column (TOSOH, Tokyo, Japan) run at $1.0 \mathrm{ml} / \mathrm{min}$ in methanol containing 4\% DDW. Data concerning the VKOR activity were fitted by nonlinear regression with the Michaelis-Menten equation. Estimations of apparent $K_{m}$ and $V_{\max }$ values were obtained by GraphPad Prism (GraphPad Software, Inc., San Diego, United States). In preliminary experiments, the protein concentration and incubation time for reactions were confirmed to keep linearity in the method described above. Also, the concentration of the substrate, VKO, was 
validated.

\subsection{VKOR inhibition study}

After the kinetic study of VKOR, we performed VKOR inhibition assay and determined the inhibitor constant, $K_{\mathrm{i}}$. The assays were done using the same procedure as the VKOR kinetic study.

In preliminary experiments, we added warfarin dissolved in DMSO at concentrations of $0.5,1,3,5$ and $10 \mu \mathrm{M}$ to clarify the rate of inhibition by warfarin in each species. Then, we chose six concentrations of warfarin including both lower and higher concentrations than the concentration that inhibited 50\% of VKOR activity in each species.

From the results of the preliminary studies (data not shown), the concentrations of the inhibitor were found to be 0.05 to $0.5 \mu \mathrm{M}$ in rats, 1.0 to $10 \mu \mathrm{M}$ in chickens and 0.1 to $1.0 \mu \mathrm{M}$ in ostriches. The reaction was performed at concentrations of 50 and $100 \mu \mathrm{M}$ of substrate (VKO). The inhibition constant $K_{i}$ was determined by the method of Dixon (1953).

\subsection{Warfarin metabolism}

Warfarin metabolism by liver microsomes was analyzed by the method of Kaminsky et al. (1979) under conditions where warfarin metabolic activity was linear. Magnesium chloride (3 mM, final concentration), G6P ( $5 \mathrm{mM}$, final concentration), and warfarin-sodium (400 $\mu \mathrm{M}$, final concentration) were mixed and added to a mixture of microsomes (diluted to be $1.0 \mathrm{mg}$ protein/ml with $\mathrm{KPB}$, final concentration) or KPB for the negative control. The total volume of each reaction mixture was $500 \mu \mathrm{l}$. Samples were pre-incubated for $5 \mathrm{~min}$. A mixture of G6PDH (2 IU/ml final concentration) and $\beta$-NADPH (0.5 mM final concentration) was 
added to each sample to start the reaction. The reaction lasted kept for $10 \mathrm{~min}$, and $20 \mu \mathrm{l}$ of $60 \%$ perchloric acid was added to stop the reaction. The temperature for pre-incubation and the reaction was $37^{\circ} \mathrm{C}$ for rats, $38^{\circ} \mathrm{C}$ for ostriches, $41^{\circ} \mathrm{C}$ for snowy owls and the great horned owl, and $42^{\circ} \mathrm{C}$ for chickens and mallards (Riviere, 1992; Siegfried et al., 1975). Samples were centrifuged at $3,000 \mathrm{~g}, 4^{\circ} \mathrm{C}$ for $10 \mathrm{~min}$, and $50 \mu \mathrm{l}$ of the supernatants were injected into the HPLC system for analysis (pump: LC-20AB (SHIMADZU), Detector: SPD-20A (SHIMADZU), Column: TSKgel-120T, $250 \times 4.6 \mathrm{~mm}, 5 \mu \mathrm{m}$ (TOSOH), Wavelength: $307 \mathrm{~nm}$, Mobile phase: consisted of $15 \mathrm{mM} \mathrm{KH}_{2} \mathrm{PO}_{4}(\mathrm{pH} 3$ adjusted with $1 \mathrm{~N} \mathrm{HCl}$ / methanol / acetonitrile (55:30:15)). The quantification of the metabolites was accomplished by the detected areas of each hydroxylated metabolite of warfarin derived from a standard curve.

\subsection{Statistical Analysis}

Data were analyzed using a conservative Bonferroni test with a significance level of $p$ $<0.05$, using JMP software (version 7.0; SAS Institute, Cary, NC, USA). The values are shown as mean $\pm \mathrm{SE}$ (standard error). 


\section{Results}

\subsection{Kinetic Parameters of VKOR activity}

Preliminary experiments showed the VKOR activity was in linear correlation with time and protein concentration. For the kinetic parameter, values of $K_{m}$ seemed similar to the data in a published research report (Lasseur et al., 2005) within a limited range up to $150 \mu \mathrm{M}$ of VKO in rat. However, in our study, the Michaelis-Menten fitted curve showed a tendency of biphasic activity in chicken, ostrich and rat liver microsomes (data not shown). This phenomenon may show that $K_{m}$ seemed to be higher at a high concentration of $150 \mu \mathrm{M}$ of VKO. Thus, we chose a concentration of VKO up to $400 \mu \mathrm{M}$ to estimate the accurate kinetic parameters. Figure 2 shows the VKOR activity in each animal, using the Michaelis-Menten equation. As expected, the $K_{m}$ values were higher than $150 \mu \mathrm{M}$ in three animals. Kinetic parameters $\left(V_{\max }, K_{m}\right.$ and $\left.V_{\max } / K_{m}\right)$ were obtained by GraphPad Prism (Table 2).

Liver microsomes of chickens showed the lowest $V_{\max }$ of the three species $(71.7 \pm 6.5$ $\mathrm{pmol} / \mathrm{min} / \mathrm{mg}$ protein). Ostriches still showed significantly lower $V_{\max }$ values than rats (157.6 \pm $20.0 \mathrm{pmol} / \mathrm{min} / \mathrm{mg}$ protein and $514.5 \pm 31.5 \mathrm{pmol} / \mathrm{min} / \mathrm{mg}$ protein, respectively). On the other hand, there was no difference in the values of $K_{m}$ among the three examined species (chicken:165.8 $\pm 41.3 \mu \mathrm{M}$, ostrich:187.5 $\pm 14.6 \mu \mathrm{M}$, rat:176.1 $\pm 14.2 \mu \mathrm{M}$ ). The large difference of $V_{\max }$ values resulted in a significant difference of $V_{\max } / K_{m}$ among liver microsomes obtained from birds and rats (chicken:0.47 \pm 0.09 , ostrich:0.87 \pm 0.18 , rat $2.9 \pm 0.1$ ).

\subsection{Determination of $K_{i}$}

The results of a Dixon plot with warfarin and $K_{i}$ values are shown in Figure 3 and Table 3, respectively. A significant difference was detected between chickens (11.3 $\pm 2.5 \mu \mathrm{M})$ 
and the other species by the Bonferroni test. Ostriches $(0.64 \pm 0.39 \mu \mathrm{M})$ showed a similar $K_{i}$ to rats $(0.28 \pm 0.09 \mu \mathrm{M})$. These results showed chicken VKOR activity was inhibited to the same extent at a 20-40-fold higher concentration than ostriches and rats.

\subsection{Warfarin metabolism}

We used five kinds of bird species (chickens, ostriches, mallards, snowy owls and a great horned owl) and rats in this experiment. For the snowy owls and the great horned owl, the number of individuals used in the experiment was two and one, respectively, and three individuals each for the other species. The metabolic activity is described based on P450 content in microsomes. The values of P450 content in each animal were $688 \pm 42.0 \mathrm{pmol} / \mathrm{mg}$ protein in rats, $355 \pm 38.6 \mathrm{pmol} / \mathrm{mg}$ protein in chickens, $372 \pm 17.0 \mathrm{pmol} / \mathrm{mg}$ protein in ostriches , $268 \pm$ $19.0 \mathrm{pmol} / \mathrm{mg}$ protein in mallards and $152 \pm 25.6 \mathrm{pmol} / \mathrm{mg}$ protein in owls (values are shown as mean \pm SE)

Chickens showed the highest warfarin metabolic activity as shown in Table 4 (1660.2 $\pm 282.9 \mathrm{pmol} / \mathrm{min} / \mathrm{nmol}$ P450). Ostriches also showed higher activity than rats (ostrich: $638.0 \pm$ $101.9 \mathrm{pmol} / \mathrm{min} / \mathrm{nmol}$ P450, rat: $196.0 \pm 13.7 \mathrm{pmol} / \mathrm{min} / \mathrm{nmol}$ P450). Other bird species showed lower activity than rats (mallard: $134.6 \pm 21.5 \mathrm{pmol} / \mathrm{min} / \mathrm{nmol}$ P450, owl: $32.0 \pm 12.0$ $\mathrm{pmol} / \mathrm{min} / \mathrm{nmol} \mathrm{P} 450$ ). Because we did not find a large difference between the warfarin metabolic activities in snowy owl and great horned owl, we combined these results for the warfarin metabolic activity of "owl" as shown in Table 4. The unique point in warfarin metabolism was that 4'-hydroxylated warfarin was the highly dominant metabolite only in bird species (70-80\% of all metabolites), while in rats, 4'-OH warfarin made up only half of all metabolites.

Other than the dominant metabolites in rat (4'-, 6- 7- 8- and 10-hydroxylated warfarin), 
we found an unique metabolite peak as detected by HPLC-UV, which can account for a big proportion of metabolites especially in owls (data not shown). We identified the metabolite to be warfarin alcohol by GC/MS. In rats, chickens and ostriches, the area of warfarin alcohol occupied less than $20 \%$ of the total area of the metabolites detected by HPLC-UV. On the other hand, the area of warfarin alcohol occupied more than half of the total area of metabolites in mallards and owls. This result shows that mallards and owls may possess a different metabolic route from not only rats, but even chickens and ostriches. 


\section{Discussion}

On Ulva Island in New Zealand, it was reported that $80-90 \%$ of an indigenous bird species were killed during rodent eradication using rodenticides (Eason et al., 2002). Although there was a need to control invasive alien species that affect native species and threaten the domestic animal population, some cases of the eradication program unexpectedly resulted in the poisoning of non-target species. Unexpected primary and secondary poisonings have occurred to a greater or lesser extent after the eradication actions targeting invasive rodents around the world. Nonetheless, the risks of rodenticides for non-target wild bird species have been invariably estimated to be low from the experimental results obtained using only chickens and limited avian species. To assess the risks of rodenticide use, we must clarify the toxicological influence of rodenticides on birds. The aim of this study was to elucidate the sensitivity of birds against warfarin. VKOR, the target molecule of warfarin, and warfarin hydroxylation activities were studied because alterations in these enzymes were reported to determine the difference between "warfarin sensitivity” and "warfarin resistance” in rats (Ishizuka et al., 2007; Lassuer et al., 2005). This report is the first to describe differences both in the features of VKOR and metabolism of warfarin of various bird species.

In present study, we used chickens and ostriches for VKOR characterization. Chickens have been studied to determine many aspects such as VKORC1 sequence and the $\mathrm{LD}_{50}$ of warfarin (Rost et al., 2009) and are often used as a representative bird species in toxicological tests. Ostriches are well-studied avians for the coagulation cascade and xenobiotic-metabolizing enzymes (Frost et al., 1999; Amsallem-Holtzman and Ben-Zvi, 1997). For the warfarin metabolism assay, we additionally added mallards and owls. Raptors such as owls were the most frequently reported animals in poisoning incidents, and their sensitivity was 
assumed to be higher than that of other birds. Meanwhile, mallards are reported to be a resistant avian species to warfarin in the same manner as chickens. In the current study, we found large inter-species differences in VKOR and warfarin-metabolism among these bird species.

VKOR, which is a target of warfarin, plays an important role in the cycle of vitamin $\mathrm{K}$ to supply the reduced form of vitamin $\mathrm{K}$ into the coagulation cascade. From our results, VKOR efficiency was high in rats, while chickens and ostriches showed relatively low enzymatic efficiency. Regarding the coagulation system, VKOR of chickens and ostriches could be thought to be a poor supplier of vitamin $\mathrm{K}$ in the coagulation system. The coagulation system or the coagulation factors of avian species can be different from mammal (Thomson et al., 2002). In ostriches, the vitamin K-dependent coagulation factors, such as factor II, IIV, IX and X, are known to have low or no activity (Frost et al., 1999).

Chickens are known to require a high dose of vitamin $\mathrm{K}$ from their diet. In addition, chickens showed elevated serum levels of vitamin K epoxide (VKO) compared with those of rats, and maintained almost the same level of the reduced form of vitamin $\mathrm{K}$ as rats (Will et al., 1992). This phenomenon indicates that chickens may possess a poor ability to reduce VKO in the vitamin K recycle system. We suggested that the degree of dependency on diet as a vitamin K source between species has a rank order of chicken $>$ ostrich $>$ rat. In the case of anticoagulant resistant rats, the higher vitamin $\mathrm{K}$ requirement in their diet was shown to be one possible mechanism of the resistance (Markussen et al., 2003). In an in vitro study, VKOR which reduces the vitamin $\mathrm{K}$ epoxide was assured to be less effective in resistant rats (Lasseur et al., 2005). Because the sensitivity to warfarin seems to depend on the ability of VKOR, which is the key enzyme of vitamin K cycle, the diet of each bird should be carefully monitored.

Surprisingly, the VKOR inhibition rate by warfarin, which is indicated as the value of the inhibitor constant $K_{i}$, differed even among bird species. Ostriches had a similar $K_{i}$ to that of 
laboratory rats, suggesting that ostrich VKOR might be markedly inhibited by warfarin. Meanwhile, chickens demonstrated a high $K_{i}$, and this agrees with the high $\mathrm{LD}_{50}$ in chickens. In the case of rats, the substitution of tyrosine at amino acid 139 in the sequence of VKORC1 has been elucidated to make a difference in the $K_{i}$ between sensitive and resistant rats and increase the $K_{i}$ value (Lasseur et al., 2005). Thus, the VKORC1 sequence in chickens was compared with the sequence of rats, but the amino acid at position 139 is tyrosine in both species (Rost et al., 2009). The chicken VKORC1 sequence is very interesting, because the amino acid substitutions have not been identified that cause an increase of VKOR $K_{i}$ toward warfarin, other than the $139^{\text {th }}$ position. Information on other bird VKORC1 sequences and structures is needed for a more accurate characterization of bird VKOR and the coagulation system.

In their warfarin metabolism assay of warfarin-resistant rats, Ishizuka et al. (2007) showed that the resistance resulted from increased warfarin metabolic activity. This study showed that the clearance rate is a very important parameter to determine the sensitivity to warfarin. For warfarin metabolism, multiple metabolic routes mediated by cytochrome P450 have been described in rats including 4'-hydroxylation by CYP2B1 and CYP2C11, 6-hydroxylation by CYP1A1 and CYP2C11, 7-hydroxylaton by CYP2C6, 8-hydroxylation by CYP1A1 and 10-hydroxylation by CYP3A2 (Guengerich et al., 1982). In chickens, the P450 isoforms that contribute to warfarin metabolism could be different from those in rats. The dominant CYP isoforms of bird species are thought to be CYP2H1/2 (resembles rat CYP2B1/2), CYP1A4/5 (resembles rat CYP1A1/2) or an inducible form that resembles rat CYP2E (Louis et al., 1993). However, this is the first report to examine warfarin metabolism using different bird species, and the specific enzymes that mediate warfarin metabolism in bird species have not yet been determined.

In chickens, the warfarin metabolic activity for 4'-, 6-, 7-, 8- and 10-hydroxylated 
warfarin was observed to be 5 -fold higher than in rats and more than twice as high as in ostriches. The high metabolic activity of chickens is in line with the $\mathrm{LD}_{50}$ data. However, we do not suggest that the most important difference between chickens and ostriches is due to the reported data that showed higher CYP1A4/5-dependent enzymatic activities in ostriches compared with chickens (Amsallem-Holtzman and Ben-Zvi., 1997). This supposition may suggest that the main enzymes that contribute heavily to warfarin metabolism in birds may be different from dominant P450 isoforms in mammals, which have been generally identified as CYP2C and CYP3A dependent enzymatic activities (Kaminsky and Zhang, 1997).

Meanwhile, owls in particular showed very little activity of warfarin metabolism compared with other bird species in five mammal-dominant metabolites (4'-, 6-, 7-, 8- and 10-OH). This result suggested that the owls may possess a low ability to detoxify anticoagulant rodenticides, which may agree with the frequency of reported poisoning accidents in these species. When owls eat rodents that are dead due to warfarin, the elimination rate of warfarin may be markedly lower than those of rodents or comparatively lower than those of other bird species. Thus owls may be one of the highest risk groups, considering their feeding habitat and their low ability to metabolize warfarin. In addition, there is a possibility that two owl species show phylogenetic species differences in toxicological sensitivity. Further toxicological study is needed for this raptor species.

Interestingly, we found a bird-unique warfarin metabolite in this study (data not shown). In all bird species, we consistently observed one unique metabolite other than the 5 major hydroxides of mammals. The metabolite was identified to be warfarin alcohol by GC/MS. The portions of the area detected by HPLC-UV in all metabolites were more than $50 \%$ in mallard and owls. This result suggests that these birds have an ability to uniquely catalyze warfarin, which is different from previous reports on rats and human (Wang et al., 1983; Rettie 
et al., 1992). Research on warfarin metabolism in bird species should focus on warfarin alcohol and the mediating enzyme as well as well-known metabolites such as 4'-OH.

In conclusion, our study revealed a clear difference in VKOR activity and $K_{i}$ among bird species. Also, we found a large difference in warfarin metabolic activity in birds. Together with these data, the contradiction of $\mathrm{LD}_{50}$ between reported poisoning accidents is explained by the wide inter-species differences of VKOR features and warfarin metabolic activity.

The relatively wide inter-species differences may be because of the wide evolutional history of birds. Further study is needed not only to characterize each individual species, but also to include phylogenetic characterizations. 


\section{Acknowledgements}

This study was supported inpart by Grants-in-Aid for Scientific Research from the Ministry of Education, Culture, Sports, Science and Technology of Japan awarded to M. Ishizuka (No. 19671001). 


\section{References}

Albert, C. A., Wilson, L. K., Mineau, P., Trudeau, S., Elliott, J. E., 2009. Anticoagulant rodenticides in three owl species from Western Canada, 1983-2003. Arch. Environ. Contam. Toxicol. Epub ahead of print.

Amsallem-Holtzman, E., Ben-Zvi, Z., 1997. Drug metabolizing enzymes in the ostrich (Struthio Camelus): Comparison with the chicken and the rat. Comp. Biochem. Physiol. Part C 116, 1, 47-50.

Boyle, C. M., 1960. Case of apparent resistance of Rattus norvegicus Berkenhout to anticoagulant poisons. Nature 188, 517-525.

Cain, D., Hutson, S., Wallin, R., 1998. Warfarin resistance is associated with a protein component of vitamin K 2, 3-epoxide reductase enzyme complex in rat liver. Thromb. Haemost. $80,128-133$

Dixon, M., 1953. The determination of enzyme inhibitor constants. Biochem. J. 55, 1, 170-171.

Dowding, J. E., Murphy, E. C., Veitch, C. R., 1999. Brodifacoum residues in target and non-target species following an aerial poisoning operation on Motuihe Island, Hauraki Gulf, New Zealand. N. Z. J. Ecol. 23, 2, 207-214.

Eason, C. T., Murphy, E. C., Wright, G. R. G., Spurr, E. B., 2002. Assessment of risks to brodifacoum to non-target birds and mammals in New Zealand, Ecotoxicology 11, 35-48. 
Empson, R. A., Miskelly, C. M., 1999. The risks, costs and benefits of using Brodifacoum to eradicate rats from Kapiti Island, New Zealand. N. Z. J. Ecol., 23, 241-254.

Erickson, W., Urban, D., 2004. Potential risks of nine rodenticides to birds and nontarget mammals: a comparative approach. Environmental Protection Agency Office of Prevention, Pesticides and Toxic Substances. Washington, D.C., USA.

Frost, C. L., Naude, R. J., Oelofsen, W., Jacobson, B., 1999. Comparative blood coagulation studies in the ostrich. Int. Immunopharmacol. 45, 75-81.

Gebauer, M., 2007. Synthesis and structure-activity relationships of novel warfarin derivatives. Bioorg. Med. Chem. 15, 2414-2420.

Guengerich, F. P., Danna, G. A., Wright, S. T., Martin, M. V., Kaminsky, L. S., 1982. Purification and characterization of liver microsomal cytochromes P-450: electrophoretic, spectral, catalytic, and immunochemical properties and inducibility of eight isozymes isolated from rats treated with phenobarbital or $\beta$-naphthoflavone. Biochemistry 21, 6019-6030.

Howald, G. R., Mineau, P., Elliott, J.E., Cheng, K. M., 1999. Brodifacoum poisoning of avian scavengers during rat control on a seabird colony. Ecotoxicology 8, 431-447.

Ishizuka, M., Okajima, F., Tanikawa, T., Min, H., Tanaka, K. D., Sakamoto, K. Q., Fujita, S., 2007. Elevated warfarin metabolism in warfarin-resistant roof rat (Rattus rattus) in Tokyo. Drug 
Metab. Dispos. 35, 62-66.

Jansing, R. L., Chao, E. S., Kaminsky, L. S., 1992. Phase II metabolism of warfarin in primary culture of adult rat hepatocytes, Mol. Pharmacol. 41, 209-215.

Johnston, J. J., Pitt, W. C., Sugihara, R. T., Eisemann, J. D., Primus, T. M., Holmes, M. J., Crocker, J., Hart, A., 2005. Probabilistic risk assessment for snails, slugs, and endangered honeycreepers in diphacinone rodenticide baited areas on Hawaii, USA. Environ. Toxicol. Chem. 24, 1557-1567.

Kaminsky, L.S., Fasco, M.J., Guengerich, F.P., 1979. Comparison of different forms of liver, kidney, and lung microsomal cytochrome P-450 by immunological inhibition of regio- and stereoselective metabolism of warfarin. J. Biol. Chem. 254, 9657-9662.

Kaminsky, L. S., Zhang, Zhi-Yi, 1997. Human P450 metabolism of warfarin, Pharmacol. Ther. 73, 67-74.

Lasseur, R., Longin-Sauvageon, C., Videmann, B., Billeret, M., Berny, P., Benoit, E., 2005.

Warfarin resistance in a French strain of rats. J. Biochem. Mol. Toxicol. 19. 6. 379-385.

Louis, C. A., Sinclair, J. F., Wood, S. G., Lambercht, L. K., Sinclair, P. R., Smith, E. L., 1993. Synergistic induction of cytochrome P450 by ethanol and isopentanol in cultures of chick embryo and rat hepatocytes, Toxicol. Appl. Pharmacol. 118, 169-176. 
Lowry, O. H., Rosebrough, N. J., Farr, A. L., Randall, R. J., 1951. Protein measurement with the folin phenol reagent, J. Biol. Chem. 193, 1, 265-275.

Omura, T., Sato, R., 1964. The carbon monoxide-binding pigment of liver microsomes, J. Biol. Chem. 239, 2370-2378.

Markussen M. D., Heiberg, A. C., Nielsen, R., Leirs, H., 2003. Vitamin K requirement in Danish anticoagulant-resistant Norway rat, Pest Manag. Sci. 59, 913-920

Petterino, C., Paolo, B., 2001. Toxicology of various anticoagulant rodenticides in animals, Vet. Hum. Toxicol. 43, 353-356.

Rettie, A. E., Korzekwa, R. K., Kunze, K. L., Lawrence, R. F., Eddy, A. C., Aoyama, T., Gelboin, H. V., Gonzalez, F. J., Trager, W. F., 1992. Hydroxylation of warfarin by human cDNA-expressed cytochrome P-450: a role for P-4502C9 in the etiology of (S)-warfarin-drug interactions, Chem. Res. Toxicol. 5, 54-59.

Richards, S. A., 1971. The significance of changes in the temperature of the skin and body core of the chicken in the regulation of heat loss. J. Physiol. 216, 1-10.

Riviere J. L., 1992. Hepatic microsomal monooxygenase activities in natural populations of the mallard duck Anas platyrhynchos, the tufted duck Aythya fujigula and the great crested grebe Podiceps cristatus. Ecotoxicology 1, 117-135. 
Rost, S., Pelz, H. J., Menzel, S., MacNicoll, A. D., León, V., Song, K. J., Jäkel, T., Oldenburg, J., Müller, C. R., 2009. Novel mutations in the VKORC1 gene of wild rats and mice - a response to 50 years of selection pressure by warfarin? BMC genet. 10, 4 .

Schmidt-Nielsen, K., Kanwisher, J., Lasiewski, R. C., Cohn, J. E., Bretz, W. L., 1969. Temperature regulation and respiration in the ostrich. Condor 71, 341- 352.

Siegfried, W. R., Abraham, R. L., Kuechle, V. B., 1975. Daily temperature cycles in barred, great-horned and snowy owls. Condor 77, 502-506.

Stone, W. B., Okoniewski, J. C., Stedelin, J. R., 1999. Poisoning of wildlife with anticoagulant rodenticides in New York. J. Wildl. Dis. 35, 187-193.

Suttie, J.W., Nelsestuen, G.L., 1980. Mechanism of action of_vitamin K: synthesis of gamma-carboxyglutamic acid. CRC Crit. Rev. Biochem. Mol. Biol. 8, 191-223.

Thijssen, H.H., Soute, B.A., Vervoort, L.M., Claessens, J.G., 2004. Paracetamol (acetoaminophen) warfarin interaction: NAPQ1, the toxic metabolite of paracetamol, is an inhibitor of enzymes in the vitamin K cycle. Thromb. Haemost. 92, 797-802.

Tishler, M., Fieser, L. F., Wendler, N. L., 1940. Hydro, oxido and other derivatives of vitamin $\mathrm{K}_{1}$ and related compounds, J. Am. Chem. Soc. 62, 2866-2871.

Thomson, A. E., Squires, E. J. , Gentry, P. A., 2002. Assessment of factor V, VII and X activities, the key coagulant proteins of the tissue factor pathway in poultry plasma, Brit. Poultry Sci. 43, 
313-321.

Vandenbroucke, V., Bousquet-Melou, A., Backer, P. D., Croubels, S., 2008. Pharmacokinetics of eight anticoagulant rodenticides in mice after single oral administration. J. Vet. Pharmacol. Ther. $31,437-445$.

Walker, L. A., Turk, A., Long, S. M., Wienburg, C. L., Best, J., Shore, R. F., 2008. Second generation anticoagulant rodenticides in tawny owls (Strix aluco) from Great Britain. Sci. Total Environ. 392, 93-98.

Wallin, R., Martin, L. F., 1987. Warfarin poisoning and vitamin K antagonism in rat and human liver. Design of a system in vitro that mimics the situation in vivo. Biochem. J. 241, 389-396.

Wang, P. P., Beaune, P., Kaminsky, L. S., Dannan, G. A., Kadlubar, F. F., Larrey, D., Guengerich, F. P., 1983. Purification and characterization of six cytochrome P-450 isozymes from human liver microsomes. Biochemistry 22, 5375-5383.

Will, B. H., Usui, Y., Suttie, J. W., 1992. Comparative metabolism and requirement of vitamin K in chicks and rats. J. Nutr. 122, 2354-2360. 
Table 1. Comparison of $\mathbf{L D}_{50}$ for warfarin and second-generation anticoagulants between animals (modified from Erickson and Urban, 2004).

\begin{tabular}{cccc}
\hline $\mathrm{LD}_{50}(\mathrm{mg} / \mathrm{kg})$ & Warfarin & Bromadiolone & Brodifacoum \\
\hline Rat (norway, roof) & 1.65 & $0.56-0.84$ & $0.39,0.56$ \\
Mouse (laboratory, house) & $4.35,11.0$ & 1.75 & 0.4 \\
Cat & $2.5-20$ & $>25$ & $<25$ \\
Dog & $20-50,200-300$ & 8.1 & $0.25-1.0$ \\
Chicken & 942 & - & 4.5 \\
Mallard & 620 & - & $0.26,4.6$ \\
Canada goose & - & - & $<0.75$ \\
Ring-necked pheasant & - & 138,170 & - \\
Northern bobwhite & $>2150$ &
\end{tabular}

Avian species seems more resistant to anticoagulants than rodents and other mammal species (Table 1.). However, the frequent poisoning incidents (especially in raptors) imply they have different susceptibility to anticoagulants compared with bird species used to estimate the LD50 data. 
Table 2. Kinetic parameters of VKOR in chickens, ostriches and rats.

\begin{tabular}{cccc}
\hline & Vmax $(\mathrm{pmol} / \mathrm{min} / \mathrm{mg}$ protein $)$ & $K m(\mu \mathrm{M})$ & $\operatorname{Vmax} / \mathrm{Km}$ \\
\hline Chicken & $71.70 \pm 6.5^{*}$ & $165.8 \pm 41.3$ & $0.47 \pm 0.09^{*}$ \\
Ostrich & $157.6 \pm 20.0^{*}$ & $187.5 \pm 14.6$ & $0.87 \pm 0.18^{*}$ \\
Rat & $514.5 \pm 31.5$ & $176.1 \pm 14.2$ & $2.9 \pm 0.10$ \\
\hline
\end{tabular}

Kinetic parameters of VKOR-dependent activities were estimated in chicken, ostrich and rat liver microsomes. The values are given as means \pm SE in each animal $(n=3)$.

*Significant difference from rats $(p<0.05)$. 
Table 3. Inhibitor constants in rats and birds.

\begin{tabular}{cc}
\hline & $K i(\mu \mathrm{M})$ \\
\hline Chicken & $11.3 \pm 2.5^{*}$ \\
Ostrich & $0.640 \pm 0.39$ \\
Rat & $0.280 \pm 0.09$ \\
\hline
\end{tabular}

Inhibitor constants, $K_{i}$, are shown in the table. Values are mean $\pm \mathrm{SE}$.

*Significant difference from ostriches and rats $(p<0.05)$. 
Table 4. Metabolic activity of warfarin into its hydroxylated form.

\begin{tabular}{ccccccc}
\hline & $4 '-\mathrm{OH}$ & $6-\mathrm{OH}$ & $7-\mathrm{OH}$ & $8-\mathrm{OH}$ & $10-\mathrm{OH}$ & Total \\
\hline Rat & $92.8 \pm 13.2$ & $48.5 \pm 2.5$ & $14.9 \pm 1.1$ & $2.3 \pm 0.5$ & $37.4 \pm 5.0$ & $196.0 \pm 13.7$ \\
Chicken & $1204.0 \pm 185.3$ & $294.5 \pm 65.0$ & $113.7 \pm 29.7$ & $43.4 \pm 7.6$ & $4.5 \pm 4.5$ & $1660.2 \pm 282.9$ \\
Ostrich & $523.4 \pm 58.2$ & $68.0 \pm 24.5$ & $17.2 \pm 7.1$ & $30.4 \pm 12.4$ & $\mathrm{ND}$ & $638.0 \pm 101.9$ \\
Mallard & $96.8 \pm 13.5$ & $18.2 \pm 3.4$ & $10.5 \pm 1.6$ & $\mathrm{ND}$ & $9.1 \pm 4.5$ & $134.6 \pm 21.5^{*}$ \\
Owl & $25.9 \pm 8.3$ & $2.6 \pm 2.6$ & $\mathrm{ND}$ & $1.5 \pm 1.5$ & $\mathrm{ND}$ & $32.0 \pm 12.0^{*} \dagger$ \\
\hline
\end{tabular}

This table shows the means \pm SE for metabolic activities to each hydroxylated form of warfarin in each animal: rat, chicken, ostrich and mallard $(n=3)$. Owl includes snowy owl $(n=2)$ and great horned owl $(\mathrm{n}=1)$.

*Significant difference from chickens $(p<0.05)$.

†Significant difference from ostriches $(p<0.05)$. 
Figure 1. Anticoagulation effect and metabolism of warfarin.

The target of warfarin is vitamin $\mathrm{K}$ epoxide reductase (VKOR). Vitamin $\mathrm{K}$ is a coenzyme for activation of prothrombin and other vitamin $\mathrm{K}$ dependent coagulation factors. An insufficient supply of vitamin K results in insufficient coagulation and hemorrhage. Warfarin is known to be metabolized by CYP and the hydroxylated warfarin and further conjugated warfarin metabolites are excreted into urine.

Figure 2. Vitamin K epoxide reductase (VKOR) activity versus various concentrations of vitamin $\mathrm{K}$ epoxide in rats, ostriches and chickens.

Assay method for VKOR activities is described in the text. Data were fitted to nonlinear regression curves with the Michaelis-Menten equation. The plots show the mean $( \pm S E) . n=3$ for each species.

Figure 3. Dixon plot to determine inhibition constant $\left(K_{i}\right)$ of warfarin in birds and rats.

The $K_{i}$ for VKOR toward warfarin was estimated in chicken, ostrich and rat liver microsomes. The $\mathrm{X}$-axis shows the warfarin concentration $(\mu \mathrm{M})$, and the $\mathrm{y}$-axis is the reciprocal of activities. The x-coordinates of intersection points show the $-K_{i}$. 
Figure 1

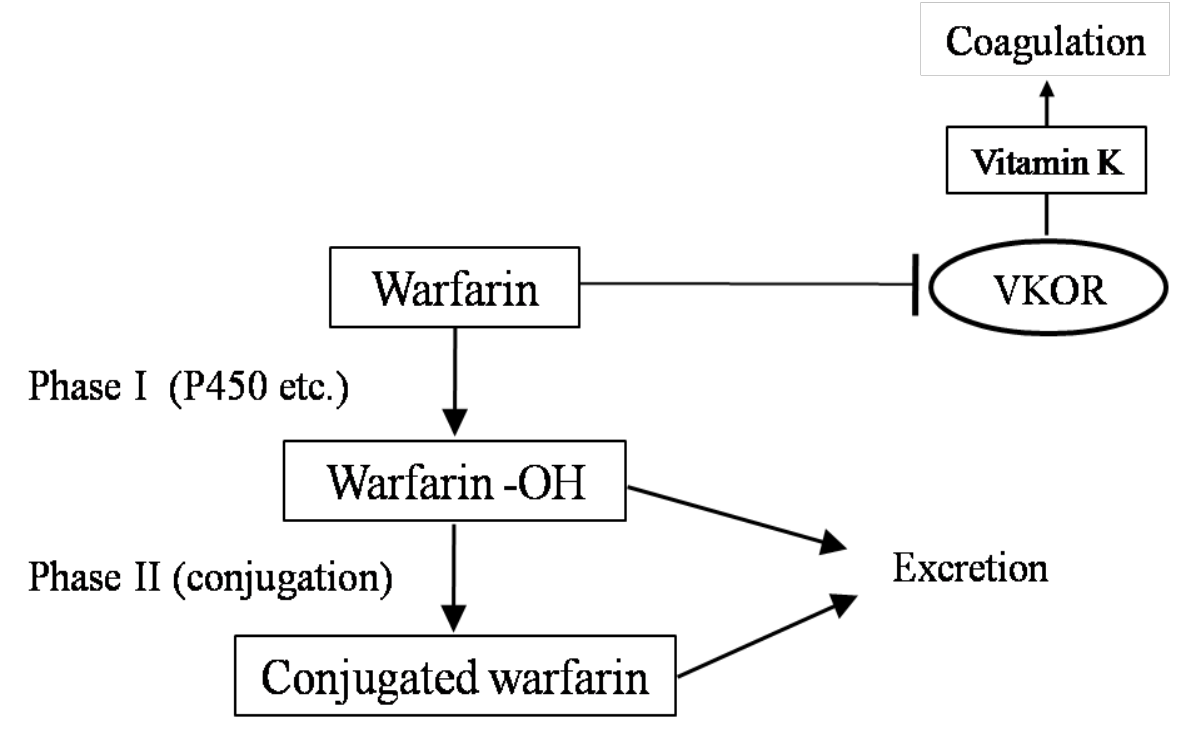


Figuire 2

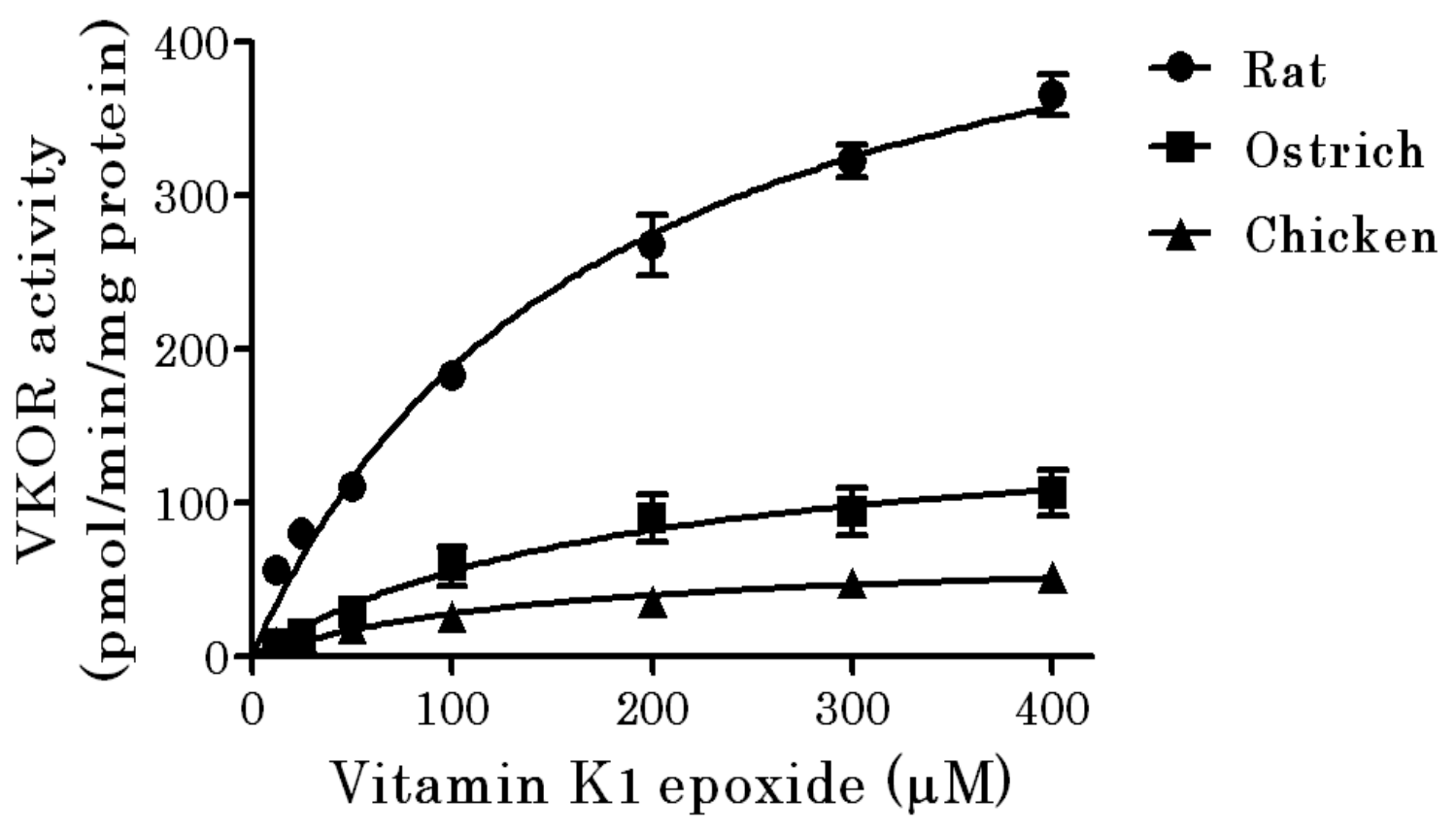


Figure 3
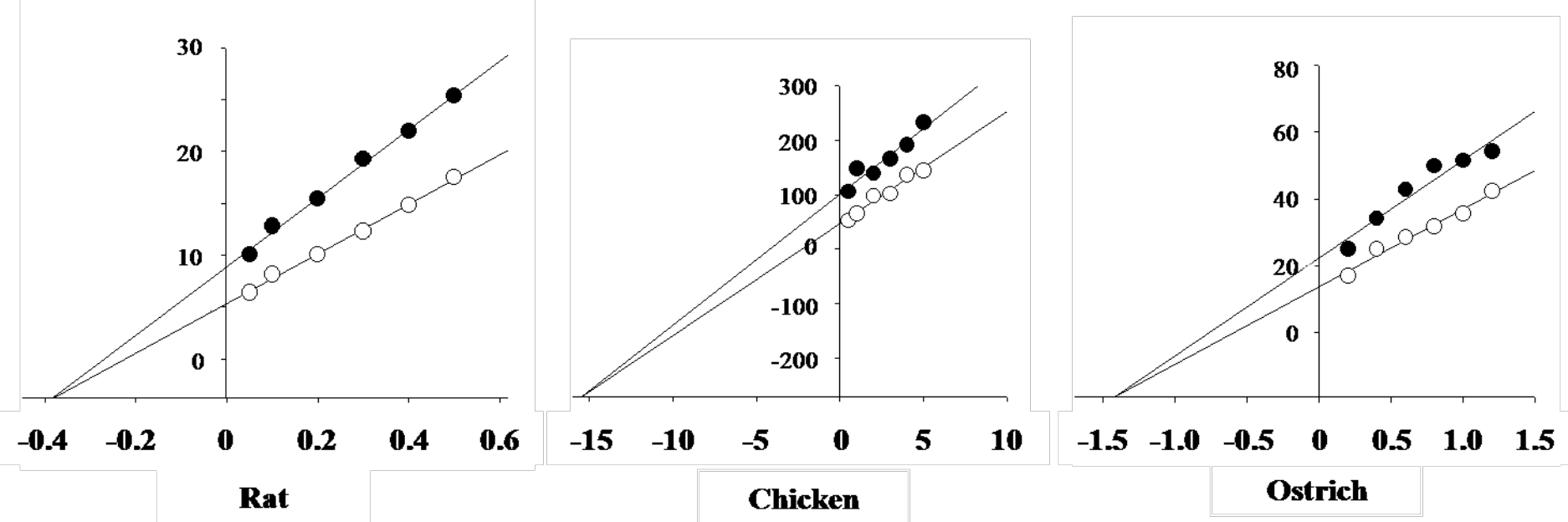